\title{
Management strategies differentially affect root functional trait expression in cocoa agroforestry systems
}

\author{
Kira A. Borden ${ }^{1,2} \cdot$ Marney E. Isaac ${ }^{1,2}$ \\ Accepted: 26 February 2019 / Published online: 19 March 2019 \\ (C) INRA and Springer-Verlag France SAS, part of Springer Nature 2019
}

\begin{abstract}
In tree-based agroecosystems, environmental heterogeneity can be high and resource acquisition strategies among individual plants can be expected to vary. This poses a challenge for appropriate nutrient prescriptions. We used a novel trait-based approach to measure in situ fine root phenotypic response of cocoa (Theobroma cacao) to fertilization. Two levels of NPK fertilizer were applied to cocoa in agroforestry, with shade trees Entandrophragma angolense or Terminalia ivorensis, or in monoculture. Four months following fertilization, cocoa fine roots were extracted from ingrowth cores and analyzed for a suite of traits positively associated with resource acquisition: fine root production, ratio of absorptive to transport roots, specific root length, specific root area, specific root tip abundance, and root nitrogen content, as well as traits positively associated with longer-lived root organs (resource conservative): root tissue density, average root diameter, and root carbon to nitrogen ratio. In surface soils $(0$ to $10 \mathrm{~cm})$, fertilization largely stimulated roots to express resource conservative strategies compared to unfertilized cocoa roots (up to 70\% mean percent difference among all root traits) but with limited measurable differences in root trait response between the two fertilization levels. In subsurface soils $(10$ to $20 \mathrm{~cm}$ ), however, inconsistent cocoa root responses to fertilization and shade trees suggested increasing complexity in nutrient acquisition strategies with soil depth. At both depths, we detected coordination among cocoa root trait variation including a resource acquisition to conservation axis explaining $\sim 45 \%$ of total trait variation, yet an individual cocoa plant's position on these coordinated trait axes was predominately affected by the shade tree rather than fertilization level. This study provides some of the first insights into intraspecific root functional trait expression to fertilization in multispecies agriculture. We show that a trait-based approach can be used to improve diagnostics and prescriptions of nutrient amendments in agroforestry systems.
\end{abstract}

Keywords Agroforestry - Functional traits - Ghana - Intraspecific trait variation - Nutrient management $\cdot$ Root economics spectrum $\cdot$ Root foraging $\cdot$ Root traits $\cdot$ Theobroma cacao

\section{Introduction}

In tropical agroecosystems, nutrient amendments are often necessary for sustaining crop production, but nutrients from fertilizers that are not acquired by plants can be a source of non-point pollution as well as an inefficiency in resource use

Marney E. Isaac

marney.isaac@utoronto.ca

1 Department of Geography and Planning, University of Toronto, Toronto, ON, Canada

2 Department of Physical and Environmental Sciences and the Centre for Critical Development Studies, University of Toronto Scarborough, Toronto, ON M1C 1A4, Canada for a farmer (Vitousek et al. 2009). Therefore, it is imperative that nutrient management strategies simultaneously support crop productivity and limit nutrient losses to the wider environment. At the same time, increasing or maintaining higher levels of biodiversity on farms is a critical management strategy employed by farmers to, in part, improve overall nutrient levels and nutrient cycling efficiencies on farms (Malézieux et al. 2009). However, even in biodiverse agroecosystems, nutrient amendments can be needed to offset the losses from harvested material. In tree-based agroecosystems in the tropics - such as in cocoa (Theobroma cacao L.) agroforests, the focus of the present study (Fig. 1) - environmental heterogeneity can be high and, thus, resource acquisition strategies among individual plants of the same species at the same site can be expected to vary, which poses a challenge for appropriate nutrient prescriptions. 
Fig. 1 Cocoa agroecosystems in Ashanti Region, Ghana, showing cocoa growing in monoculture (left panel) and growing in agroforestry with a shade tree (Terminalia ivorensis)
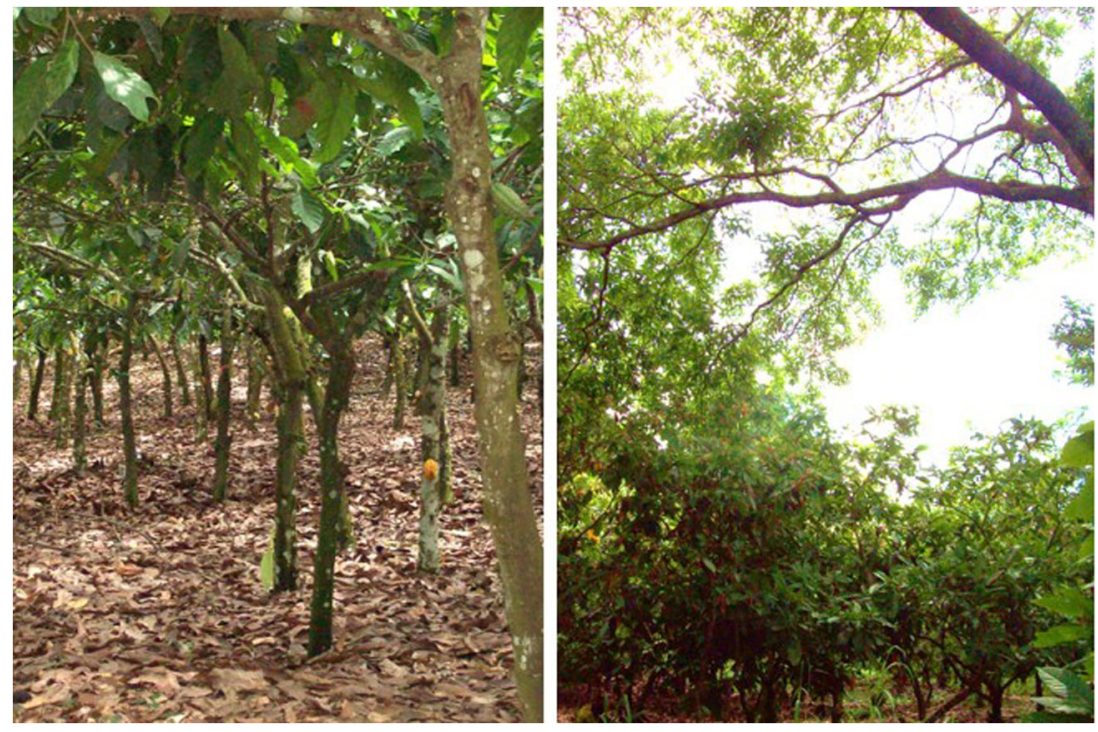

Assessing root functional trait response to various management strategies may serve as important proxy to plants' capacity to adjust to management interventions, such as fertilization or planned species diversity. Indeed, systematic intraspecific trait variation in roots has been observed along fertilized nutrient gradients (Mou et al. 2013; Eissenstat et al. 2015; Wang et al. 2016, 2017; Chen et al. 2017). For example, plants will construct longer-lived root organs where soil is enriched with nutrients. This trend can be empirically assessed using functional root traits that are known to be positively related to root longevity: diameter (D; mm) (Eissenstat et al. 2015; Yan et al. $2017)$ and the ratio of carbon to nitrogen $\left(\mathrm{C}: \mathrm{N}_{\text {root }}\right)$ (Chen et al. 2017), which are root traits typically defined as resource conserving. At the same time, greater investment to fine root tissues also results in a decrease in root trait values typically defined as resource acquiring. These traits are generally positively related with nutrient uptake rates and root turnover: specific root length (SRL; $\mathrm{m} \mathrm{g}^{-1}$ ), specific root tip abundance (SRTA; tips $\mathrm{g}^{-1}$ or comparable trait describing branching intensity) (Ostonen et al. 2007; Eissenstat et al. 2015; Chen et al. $2017)$, as well as the nitrogen content of roots $\left(\mathrm{N}_{\text {root }}\right)$, which is associated with metabolic processes in the root (i.e., nutrient uptake) (Freschet and Roumet 2017). Other studies, however, have shown opposite trends with soil resource availability (Fort et al. 2016; Bordron et al. 2018) and newly emerging research has revealed functional specialization of roots for acquiring specific nutrients of different mobilities at different depths (Bordron et al. 2018). Under naturally heterogeneous soil nutrient environments, cocoa intraroot system trait variation in relation to soil nutrients has been shown to be nutrient specific (Borden et al. 2019) but also dependent on interactions with con- or heterospecific neighbor trees (Isaac et al. 2014), thus leading to further questions on the interactive nature of soil amendments and species combination on root trait expression in tree-based agroecosystems.
Inherent genotypic constraints in root phenotypic plasticity will limit root response to nutrients, and consequently, the extent and direction of root trait response to increased nutrient availability (Eissenstat et al. 2015). At these phenotypic limits, the capacity for plants to match uptake of nutrients with increasingly elevated nutrients in soil is expected to be constrained. Furthermore, it is unlikely that these root trait responses occur independently from one another and, thus, understanding the covariation among multiple traits measured on the same individual may describe critical trade-offs in plant growth and construction. An illustrative example is the "root economics spectrum," which places individuals that express more resource conserving strategies opposite to individuals that express more resource acquiring strategies (Isaac et al. 2017). Analyses of root traits and coordinated root trait variation have characterized resource acquisition strategies across soil nutrient availability gradients (Weemstra et al. 2017) and, importantly, trade-offs in resource acquiring versus conserving strategies have been reported among individuals of the same species (e.g., in Cunninghamia lanceolata (Wang et al. 2016) and in a crop species Coffea arabica (Isaac et al. 2017)). However, additional spectra or dimensions of coordinated trait variation in roots have also been found (Kong et al. 2014; Prieto et al. 2015; Liese et al. 2017) likely due to the complex role of roots in soil, which can vary, for example, with soil depth (Yan et al. 2017; Bordron et al. 2018) and with interactions with neighboring plants (Isaac et al. 2017).

Farm-scale heterogeneity can be largely controlled by management, such as species composition, which in turn can affect how roots respond to fertilization. For example, McGrath et al. (2001) reported that roots of Theobroma grandiflorum cultivated on P-limited soils in the Amazon preferentially grew in P-fertilized soil but that this growth response was affected by heterospecific neighboring trees. Wang et al. (2016) reported that coordinated root strategies in C. lanceolata were modified 
by nutrient amendments as well as thinning and pruning practices. However, other than root placement and growth, it is unknown how combined management effects of fertilization and species composition can modify root intraspecific trait variation in root morphology and chemical traits, particularly in the humid tropics, nor how these effects are reflected in coordinated resource acquisition strategies.

Our study has the following objectives: (1) to determine the extent and direction of intraspecific root trait response to fertilization and (2) to assess if interspecific interactions (i.e., species combination) are important in modifying intraspecific root trait response. We also aim to determine (3) the overall resource acquisition strategies among individual cocoa at the same site assessed by coordinated root trait spectra and (4) the importance of management (species combination and fertilization) in controlling the expression of these strategies. We hypothesize that fine roots will preferentially grow into fertilized soil and that these fine roots will have more conservative morphology, but the extent of trait and coordinated trait responses will be modified by species combination due interspecific effects on nutrient demands. We carried out a manipulative fertilization experiment to measure root traits on similar-aged roots in a tropical agroforest featuring same-age and same-genotype stand of cocoa. The roots collected in this study environment were assumed to be responding directly to fertilization, but within limits of the studied genotype and environmental conditions invoked by species combination.

\section{Materials and methods}

\subsection{Site description}

This study was conducted on a research site $\left(6^{\circ} 36^{\prime} 37^{\prime \prime} \mathrm{N} 0^{\circ}\right.$ $58^{\prime} 10^{\prime \prime} \mathrm{W}$ ) consisting of even-aged, 15-year-old cocoa (diameter at breast height $(\mathrm{DBH})=12.4 \pm 2.8 \mathrm{~cm}$; height $=6.1 \pm$ $1.1 \mathrm{~m})$ at a density of 1111 trees ha ${ }^{-1}$ in monoculture or interspersed with 15-year-old shade trees that are commonly selected by farmers in the region: Terminalia ivorensis (a fastgrowing pioneer species) $(\mathrm{DBH}=58.8 \pm 3.8 \mathrm{~cm}$; mean $\pm \mathrm{SE})$ and Entandrophragma angolense (a slower growing hardwood species $)(\mathrm{DBH}=19.9 \pm 1.4 \mathrm{~cm})$ that were planted at a density of 68 trees ha ${ }^{-1}$. The site consists of Acrisol soils with a sandy clay loam texture and a bulk density of $1.22 \pm$ $0.16 \mathrm{~g} \mathrm{~cm}^{-3}( \pm \mathrm{SD} ; n=9)$ between 0 and $10 \mathrm{~cm}$ and $1.47 \pm$ $0.14 \mathrm{~g} \mathrm{~cm}^{-3}$ between 10 and 20-cm soil depth, determined using a metal corer of known volume and calculating the soil moisture content of soils after oven drying for $48 \mathrm{~h}$ at $105^{\circ} \mathrm{C}$. The experiment occurred over the latter half of the rainy season (July through October), which coincided with the second peak of cocoa pod production, and roots were collected prior to the dry season. No fertilizer had been applied at the site prior to the experiment.

\subsection{Experimental design}

The experiment was established as a split-plot design with triplicate replication for each treatment combination. The main plot factor was cocoa in three species combinations: cocoa in monoculture, cocoa in mixture with $E$. angolense, and cocoa in mixture with $T$. ivorensis. Within each species combination, fertilizer was applied at two levels plus control plots with no fertilizer added. Thus, in total, 27 cocoa trees were selected with the requirement that trees appeared healthy and structurally representative for trees at the site. To measure cocoa root response to mineral nutrients, opposed to an overall tree nutrient status response from widespread fertilization, fertilization plots of dimensions $2 \times 1 \mathrm{~m}$ were established between the selected cocoa and neighbor tree, with center of each plot located $1.5 \mathrm{~m}$ from the study tree and neighbor tree and oriented perpendicularly to the transect between the stems. After installing root ingrowth cores (see Sect. 2.3), multinutrient fertilizer (15-15-15 NPK granular fertilizer; $15 \% \mathrm{~N}\left(6.5 \% \mathrm{NO}_{3}{ }^{-} \mathrm{N}\right.$ and $8.5 \% \mathrm{NH}_{4}{ }^{+}-$ N) $+15 \% \mathrm{P}_{2} \mathrm{O}_{5}+15 \% \mathrm{~K}_{2} \mathrm{O}+2 \% \mathrm{MgO}+0.1 \% \mathrm{Zn}$ ) was broadcast applied at (i) moderate fertilization $\left(187.5 \mathrm{~kg} \mathrm{ha}^{-1}\right)$ or (ii) high fertilization $\left(375 \mathrm{~kg} \mathrm{ha}^{-1}\right)$. Fertilizer levels were characterized by recommended fertilizer dosages for this region (Isaac et al. 2007; van Vliet and Giller 2017). High fertilizer delivered an influx of nutrients representing $49,51,14$, and $2 \%$ increases above available $\mathrm{N}\left(\mathrm{NO}_{3}{ }^{-}+\mathrm{NH}_{4}{ }^{+}\right)$, available $\mathrm{P}$, exchangeable $\mathrm{K}$, and exchangeable $\mathrm{Mg}$ in native soil, respectively (based on soil nutrients measured near the time of fertilization). Plots of the same dimensions were established in each of the three species combinations to measure fine roots that grew in native soil (i.e., trees without fertilization plots). Surface roots $(0-$ to $10-\mathrm{cm}$ depth) and subsurface roots (10- to 20-cm depth) were analyzed separately due to expected differences in surface-applied fertilizer with depth, driven by nutrient mobilities in soil and nutrient interception, particularly by roots in the top $10 \mathrm{~cm}$ of soil where cocoa fine root density is distinctly highest (Isaac et al. 2014: Borden et al. 2019).

\subsection{Root ingrowth cores}

In each fertilization plot, two ingrowth cores (mesh size $2 \mathrm{~mm}$ ) were deployed prior to application of fertilizer. Soil and roots were removed using a $7-\mathrm{cm}$ diameter auger, incrementally to avoid compaction of soil, to $20-\mathrm{cm}$ depth. Roots were removed, and then root-free soil was replaced into ingrowth bags that lined the soil cores. Soil was replaced by depth increments to emulate initial soil conditions. Leaf litter was removed for fertilizer application but replaced for the duration of the experiment. After 4 months, ingrowth cores were removed by digging into soil around the bags and cutting roots at the mesh interface. Samples were stored in polyethylene bags and frozen until processing. Samples were divided into depth intervals of 0 to $10 \mathrm{~cm}$ (for "surface" roots) and 10 to $20 \mathrm{~cm}$ (for "subsurface" roots). 


\subsection{Fine root traits}

Fine roots $(<2-\mathrm{mm}$ diameter) of cocoa were extracted from soil samples with forceps after handwashing over a sieve. These roots were then placed in petri dish of reverse osmosis water to loosen and remove soil particles from roots. Cocoa roots were visually identified by color, texture, and morphology using a stereoscopic microscope. Non-cocoa roots (i.e., shade tree roots and weed roots) had distinctive visual characteristics, particularly third order and higher fine roots which were used to trace to lower order roots, and led to high confidence in identifying cocoa roots. We identified and removed any non-cocoa roots from our samples and subsequent analysis in order to focus on intraspecific root trait variation of, exclusively, cocoa, which we assumed to originate from the individual cocoa tree adjacent to each fertilization plot. In monoculture, we assumed that fine roots in ingrowth cores located between two cocoa trees captured fine roots of two cocoa trees equally and thus we applied a correction factor of 0.5 to fine root biomass to derive comparable values on a tree basis across the species combination treatments. Cleaned roots were scanned using a flatbed scanner (STD4800; Regent Instruments Inc., Canada) at 800 dpi. Images were analyzed in WinRHIZO (2009; Regent Instruments, Canada) to quantify fine root length, average diameter, and number of tips. Dry weight biomass was determined after $48 \mathrm{~h}$ of drying at $65^{\circ} \mathrm{C}$. Carbon and nitrogen contents of roots were determined using combustion analysis on a $\mathrm{CN}$ analyzer (C:N 628, LECO Instruments, Canada). From these data, we could calculate fine root production (FRP; $\mathrm{mg} \mathrm{cm}^{-3} 4-\mathrm{month}^{-1}$ ), specific root length $\left(\mathrm{m} \mathrm{g}^{-1}\right.$ ), specific root area (SRA; $\mathrm{cm}^{2} \mathrm{~g}^{-1}$ ), specific root tip abundance (tips $\mathrm{g}^{-1}$ ), and the nitrogen content in root tissues $\left(\mathrm{N}_{\text {root }}\right)$ to capture root traits positively related with soil resource acquisition. We also calculated the ratio of absorptive root length to transport root length (A:T) (i.e., relative amount of ephemeral fine roots that are predominantly responsible for nutrient uptake) by using a diameter cutoff that captured most of the first three orders (Roumet et al. 2016) based on cocoa root data from this site: fine roots of cocoa below a cutoff of $0.50 \mathrm{~mm}$ generally did not exhibit secondary growth and represented $85.2 \pm 0.07 \%$ ( $\pm \mathrm{SD} ; n=30$ ) of absorptive (root orders one to three) length. To characterize conservative acquisition strategies that are positively related with root longevity, we calculated root tissue density (RTD; $\mathrm{g} \mathrm{cm}^{-3}$ ), average fine root diameter $(\mathrm{D} ; \mathrm{mm})$, and the carbon to nitrogen ratio $\left(\mathrm{C}: \mathrm{N}_{\text {root }}\right)$. Traits were selected a priori based on previously described patterns in root resource acquisition strategies (Freschet and Roumet 2017).

\subsection{Statistical analysis}

All statistical analyses were performed in R v. 3.2 .4 (R Foundation for Statistical Computing, Austria). The trait values of roots removed from ingrowth cores in the same fertilization plot were averaged and used in all subsequent analyses: i.e., trait values representative of an individual cocoa. Analyses were completed separately for roots sampled from the two depth intervals (i.e., surface and subsurface roots). To test for a response of fine roots to nutrient additions, we ran unpaired two-sample $t$ tests of the fine root trait values of cocoa in fertilization plots compared to non-fertilized plots. The trait response was quantified as the percent difference between root trait values in the fertilization plots from mean trait values of the non-fertilized plots (similar to the response ratio calculated in Ostonen et al. (2007)). To describe coordinated root trait variation (i.e., resource acquisition strategies), principal component analysis (PCA) in the "ade4" package was used to identify axes that best represent the combined variance of all measured root traits of individual cocoa. All variables were centered and scaled to unit variance prior to analysis. Principle component scores were used to evaluate the extent to which management (i.e., species combination and fertilization) influenced the relative position of individual cocoa on the dominant axes. Two-way ANOVA was used to test if there were differences in the overall position of cocoa on these axes among species combination, fertilization level, or if there were interaction effects. Prior to parametric tests, data were tested for normality of residuals using the Shapiro-Wilk test, and equality of variance among groups was tested using the Bartlett test. Root trait data were $\log _{10}$ transformed when required to improve residual normality and reduce heteroscedasticity. The level of significance was $p<0.05$ and marginal significant response considered at $p<0.1$.

\section{Results and discussion}

\subsection{Extent and direction of intraspecific root trait shifts following fertilization}

More cocoa fine roots grew into fertilized plots within a resource constrained agroecosystem (Fig. 2): FRP in the top $10 \mathrm{~cm}$ was $24.3 \pm 4.73 \mathrm{~g} \mathrm{~m}^{-2} 4$-month $^{-1}$ (mean $\pm \mathrm{SE}$ ) with no fertilization and $33.4 \pm 6.7$ and $34.5 \pm 5.2 \mathrm{~g} \mathrm{~m}^{-2} 4$-month ${ }^{-1}$ after moderate and high fertilization, respectively. At the same time, newly grown surface roots had more conservative morphology in fertilized plots. Specifically, fertilization generally lowered acquisitive trait values: A:T, SRTA, SRL, and SRA, and stimulated conservative trait values: $\mathrm{D}$ and $\mathrm{C}: \mathrm{N}_{\text {root }}$ in surface roots (Fig. 2). Directional trends in root morphological variation in this experiment are similar to those reported in long-term field fertilization and controlled laboratory experiments (Ostonen et al. 2007; Kramer-Walter and Laughlin 2017). These findings support our first hypothesis and suggest that where nutrients become more abundant, plants will invest in longer-lived root tissue. Overall, trait shifts in C: $\mathrm{N}_{\text {root }}$ were 

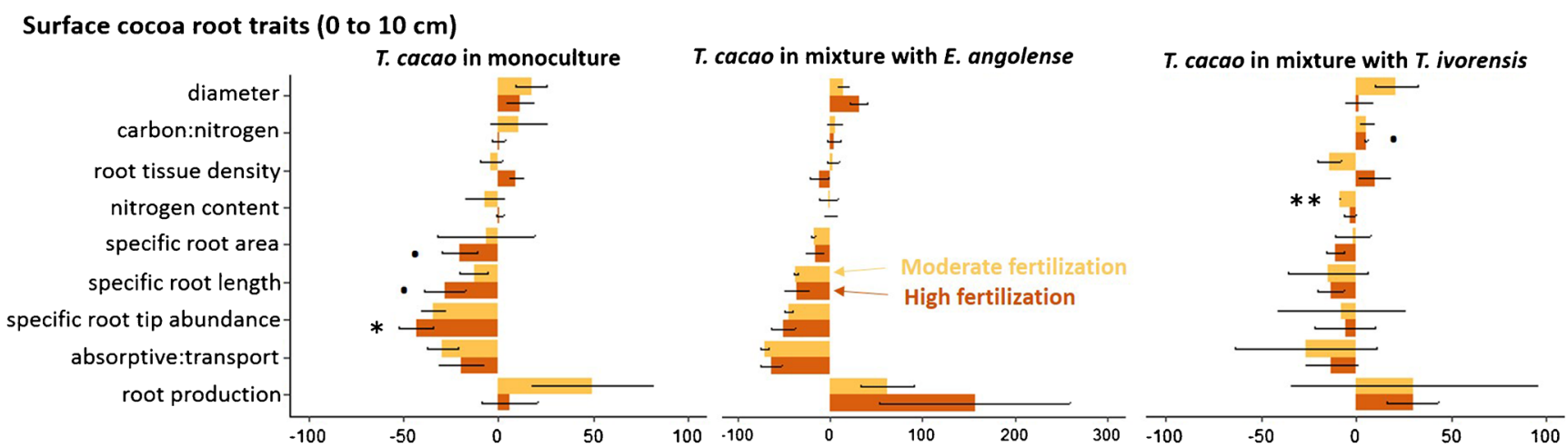

Subsurface cocoa root traits $(10$ to $20 \mathrm{~cm})$
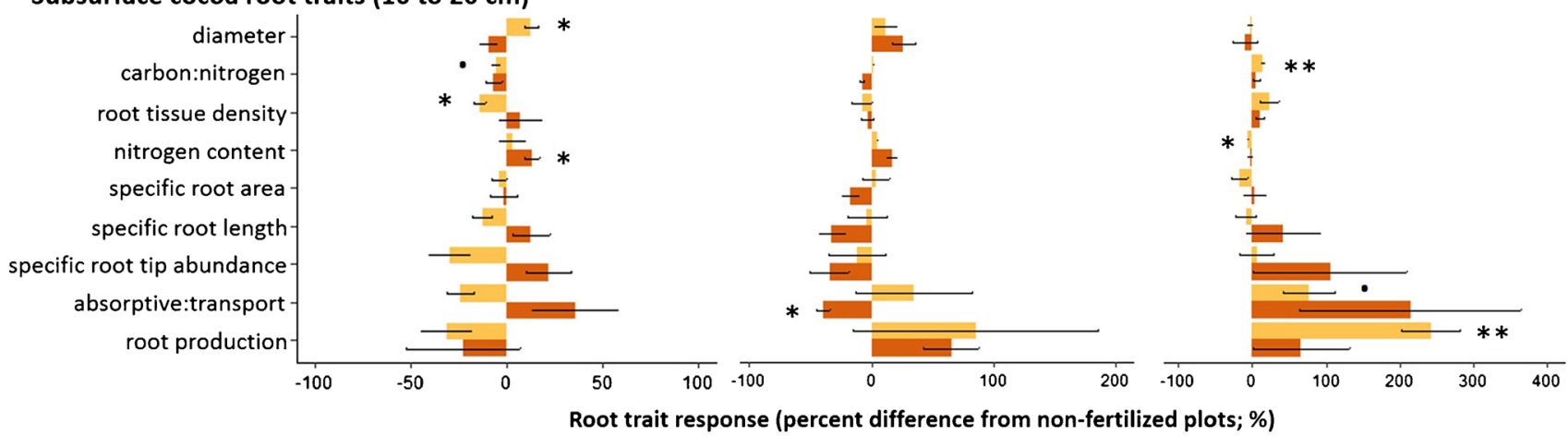

Fig. 2 Root trait response to nutrient influx (mean \pm SE percent difference from roots in non-fertilized soil) of cocoa in three different species combinations. Top row shows data of surface roots, and bottom row shows data from subsurface roots. Zero on the $x$-axes signifies no

difference in the root trait values from non-fertilized plots. Results from $t$ tests between fertilized and non-fertilized groups shown $(* * p<0.01$; $* p<0.05 ; p<0.1)$

minimal but positive ( 0 to $10 \%$ increase) as hypothesized. There were also small but inconsistent trait shifts in $\mathrm{N}_{\text {root }}$ and RTD (Fig. 2). The magnitude in shifts of root trait values was most pronounced for FRP, A:T, and SRTA, which parallel results from other studies that show architectural traits and root branching to be highly responsive to soil environment (Kong et al. 2014; Liese et al. 2017).

Observed trait shifts in surface roots within each species combination were generally consistent regardless of fertilization level. Shifts in root trait values in response to increased soil nutrients are presumably non-linear and limited in extent. Wang et al. (2017) reported a hump-shaped curve of root morphological and hydraulic trait values in Pinus tabuliformis seedlings in response to a gradient of $\mathrm{N}$ levels. Similarly, Einsmann et al. (1999) found rooting densities across multiple species to peak at intermediate fertilization levels and be suppressed at high levels. Therefore, the fertilizer dosages used in this study may characterize a limit of root trait response for cocoa in this environment. With a larger pulse of nutrients, the potential gains from variation in morphology to acquire nutrients could be less economical for the plant. Based on preexperimental measurements of root length density, cocoa fine roots had reached $46 \%$ in surface (0 to $10 \mathrm{~cm})$ and $100 \%$ in subsurface $(10$ to $20 \mathrm{~cm})$ root length density at the end of the four-month experiment (surface
0.73 of $1.59 \mathrm{~cm} \mathrm{~cm}^{-3}$; subsurface 0.41 of $0.40 \mathrm{~cm} \mathrm{~cm}^{-3}$ ). Over a longer period of time, more fine roots would be expected to grow into surface soils and increase root access to soil nutrients. However, given our root trait findings in these agroforests, when fertilizer additions are beyond the nutrient demands of the crop and/or the capacity of the crop roots to acquire those nutrients, there is likely to be a reduction in overall nutrient use efficiency and a potential risk of nutrient loss from the farm. Tracking root trait response to nutrient additions in agroforestry systems can enhance farm-level diagnostics and nutrient regime prescriptions for nutrient efficient agroforests. As we show in this study, assessing shortterm interactive effects on crop performance via functional trait expression and coordinated trait variation provides critical insights into plant-soil environment feedbacks. When baseline soil nutrient levels are elevated, such as in highinput cultivation systems, differential response of roots to patches of fertilizer may occur when investment to longerlived root organs is no longer efficient for the crop. Undoubtedly, applying this trait-based approach to assess long-term interactive effects, particularly on farms with repeated fertilization and with strong intra- and interannual variation (Muñoz and Beer 2001; van Vliet and Giller 2017), will also elucidate key mechanisms underpinning crop performance and therefore requires further extended studies. 
Structural and functional complexity in tree-based agroecosystems can influence resource availability. We found that cocoa fine root response to fertilization was mediated by species combination. For surface roots of cocoa in monoculture, the hypothesized shifts in root trait values were generally observed. Notably, cocoa roots had significantly or marginally significantly lower SRA, SRL, and SRTA after high fertilization, with 20,28 , and $43 \%$ decreases in these trait values, respectively (Fig. 2). Shifts in root trait values for cocoa in mixture with $T$. ivorensis also support our hypothesis, but only for chemical traits were these significant: $\mathrm{C}: \mathrm{N}_{\text {root }}$ showed a marginally significant increase of 5\% under high fertilization and a marginally significant decrease of $9 \%$ in $\mathrm{N}_{\text {root }}$ after moderate fertilization (Fig. 2). There were no significant shifts in trait values observed for surface roots of cocoa in mixture with $E$. angolense. However, the direction of percent changes in trait values did follow our hypothesized response to fertilization, including a $25 \%$ or greater decrease in mean trait values of A:T, SRTA, and SRL, and corresponding increase in $\mathrm{D}$ (except $\mathrm{D}$ at moderate fertilization, which increased by 14\%) (Fig. 2). We speculate that cocoa in mixture with E. angolense was not as constrained by nutrient limitation(s) compared to cocoa in the other species combinations. This assertion was also suggested in another study at the same site, where cocoa root traits in mixture with $E$. angolense also exhibited limited relationships with nutrients under field conditions (Borden et al. 2019).

More consistent trait shifts occurred in surface roots compared to subsurface roots, which presumably was, in part, due to more direct nutrient interception by shallower roots. Given that fertilizers are typically applied to the surface of soils, a pronounced effect in roots nearest the surface is expected, especially with shallow-rooted species such as cocoa. However, the response pattern in subsurface roots is intriguing as trait shifts were directionally inconsistent between fertilization levels as well as being largely dependent on neighbor species. In subsurface roots, the expected shifts in trait values were observed for cocoa in mixture with $E$. angolense but only following high fertilization, and only significantly for A:T (40\% decrease) (Fig. 2). A similar pattern emerged for cocoa in monoculture but only at moderate fertilization with a significant $14 \%$ increase in $\mathrm{D}$, while after high fertilization, the directions of trait value shifts were reversed towards higher acquisitive trait values, with a significantly $13 \%$ higher $\mathrm{N}_{\text {root }}$. The largest trait response was in the substantial increase in FRP of subsurface roots of cocoa in mixture with T. ivorensis after moderate fertilization ( $242 \%$ increase). Following high fertilization, there was also large positive shifts in acquisition traits for cocoa subsurface roots when in mixture with $T$. ivorensis, where SRL increased by $42 \%$, SRTA increased by $105 \%$, and A:T by over $214 \%$ although these were not significant (Fig. 2). Findings from our study point to differential interactions with neighboring trees and nutrient availability with depth. Notably, acquisition traits of subsurface roots of cocoa in mixture with $T$. ivorensis increased dramatically following fertilization. This may indicate where root trait plasticity may be advantageous for cocoa when next to a shallow-rooted pioneer species. We found few shade tree roots after a 4-month ingrowth experiment $(\leq$ $0.01 \mathrm{~cm} \mathrm{~cm}^{-3}$ in all fertilization treatments for both shade tree species), and thus, the present study is limited to evaluate direct effects of shade root activity. However, previous studies have shown cocoa to have a plastic response to $T$. ivorensis within the top $30 \mathrm{~cm}$ of soil (Isaac et al. 2014). Some large shifts in trait values in subsurface roots countered the hypothesized response. In these cases, cocoa roots may be demonstrating a nutrient-specific response to more mobile nutrients such as $\mathrm{NO}_{3}{ }^{-}$(presumably from increased nutrient leaching) through preference for root traits that lead to faster nutrient uptake (i.e., acquisitive root traits). Little is known on ionspecific root functional trait response but, in another study, we observed divergent root trait variation in relation to the form of soil $\mathrm{N}$; soil $\mathrm{NO}_{3}{ }^{-}$induced acquisitive root trait expression and soil $\mathrm{NH}_{4}{ }^{+}$induced conservative root trait expression (Borden et al. 2019). In the present study, we were interested in the overall root response to NPK fertilizer, containing both forms of $\mathrm{N}$, and consequently, we cannot tease out nutrient- or ion-specific responses. Characterization of nutrient-specific relationships with root trait expression is an important avenue for future studies.

\subsection{Coordinated resource acquisition strategies in a multispecies agroecosystem}

In an economically important tree crop, cocoa, at the same site, we found the expected root trait trade-off, known as the root economics spectrum (Liese et al. 2017; Isaac et al. 2017). The dominant coordinated trait axis (PC1) captures this tradeoff; cocoa with root traits associated with greater resource uptake given lower biomass investment (i.e., acquisitive traits) were aligned in opposition to cocoa expressing root traits that are associated with higher investment into longer-lived root tissues (i.e., conservative traits). Specifically, this trade-off shows individual cocoa with higher specific root length, specific root tip abundance, and the ratio of absorptive to transport roots aligning in opposition to cocoa with thicker diameter and higher $\mathrm{C}: \mathrm{N}_{\text {root }}$ (Fig. 3). The first axis explained over $40 \%$ of fine root trait variation among individuals of cocoa regardless of depth interval. Recent research of Coffea arabica suggests that coordinated leaf trait variability may be weakened by fertilization (Martin et al. 2016), but this has not been tested for roots and very little is known on coordinated root traits among individuals of the same species at local scales (Isaac et al. 2017). In the present study, cocoa were grown in tropical nutrient-limited soils that had not been 
Ordination of cocoa surface root traits $(0$ to $10 \mathrm{~cm})$
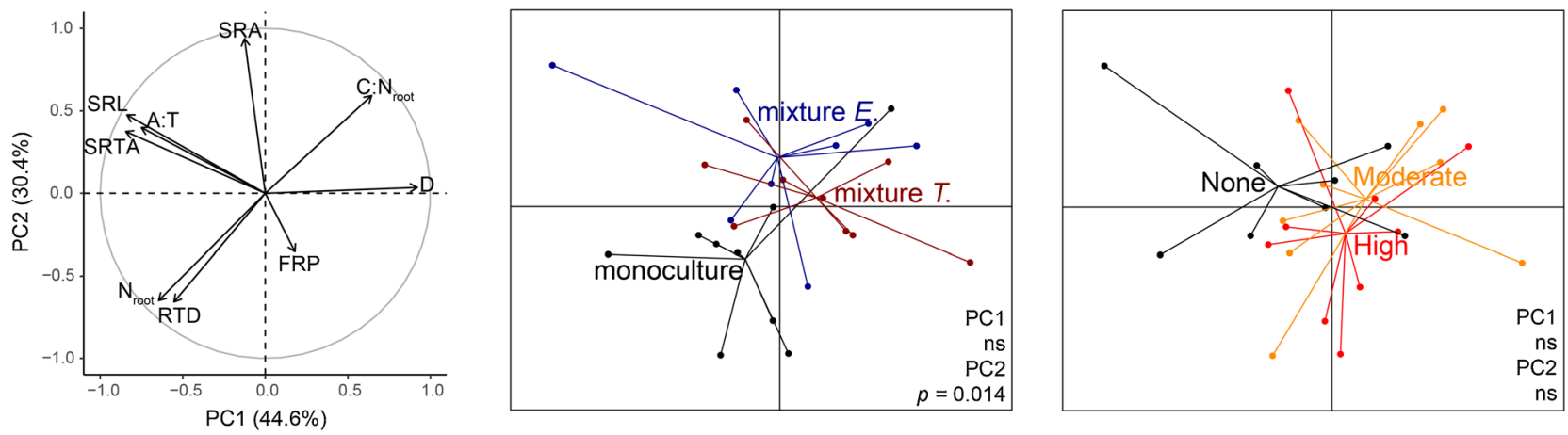

Ordination of cocoa subsurface root traits $(10$ to $20 \mathrm{~cm}$ )

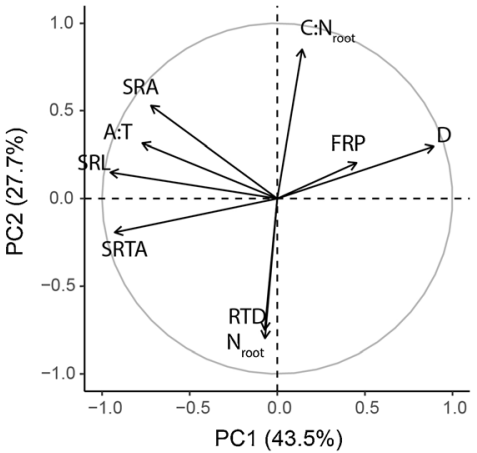

Fig. 3 Ordination of cocoa surface roots (top row) and subsurface roots (bottom row) from principal component analysis (left panels) and resulting biplots of axes scores grouped according to species composition (middle panels: cocoa in monoculture, cocoa in mixture
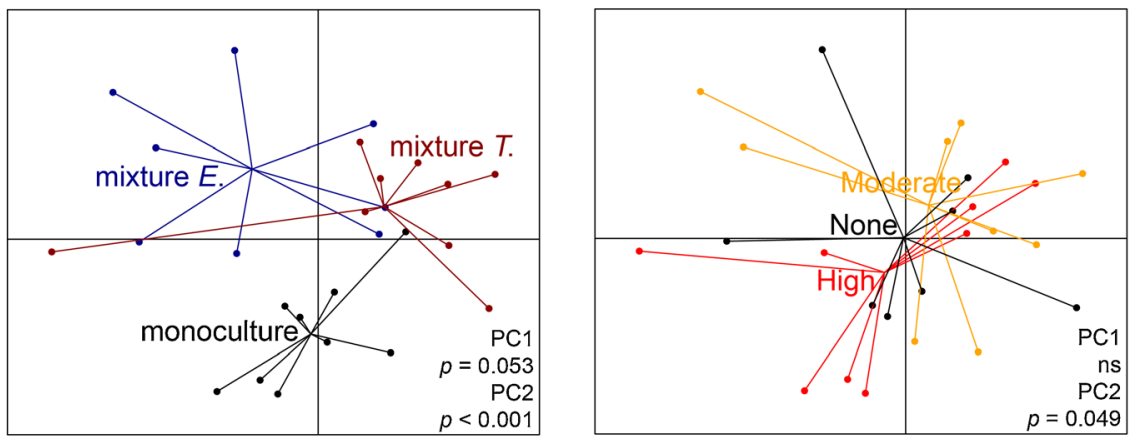

with $E$. angolense or cocoa in mixture with $T$. ivorensis and fertilization level (right panels). Results from two-way ANOVA are presented; there were no interactive effects of species composition and fertilization (Table 2) previously fertilized and, thus, local nutrient heterogeneity and subsequent variation in resource acquisition strategies can be expected.

Tree species composition will affect the quantity and quality of inputs (e.g., litter fall, cocoa husks residues, root inputs), which results in a complex delivery of bioavailable nutrients in the soil, resulting in altered nutrient status in plants (Isaac et al. 2007) and soil, and in turn, the root response to nutrient influx is expected to vary. We found that neighbor species controlled coordinated root trait syndromes in cocoa, suggesting that the abiotic and biotic conditions invoked by different species of trees can lead to variation in the overall resource acquisition strategies of cocoa. Overall, species composition, as compared to fertilization, more strongly controlled coordinated trait variation for cocoa and there were no significant interactive effects of species combination $\times$ fertilization level on coordinated root trait syndromes at either depth (Table 2). In surface roots, cocoa next to shade trees tended towards higher PC1 values (more conservative on the root economics spectrum) compared to cocoa in monoculture, but this was non-significant ( $p=0.286$ ) (Table 2; Fig. 3). Similarly, in surface roots, cocoa fine roots in fertilized plots tended to express more conservative strategies than fine roots in the nonfertilized plots, but this was non-significant (PC1 axis scores; $p=0.153$ ). In subsurface roots, there was a marginally significant species combination effect on PC1 $(p=0.053)$ (Table 2), with subsurface roots of cocoa in mixture with $T$. ivorensis significantly higher than cocoa subsurface roots in mixture with $E$. angolense ( $p=0.044)$. Similarly, location of individual $C$. arabica along a root economics spectrum was reported to be partially explained by shade tree management practices (Isaac et al. 2017).

Unlike in leaf traits which often coordinate on a dominate leaf economics spectrum (including in crop plants (Martin et al. 2016; Isaac et al. 2017)), it is increasingly recognized that root resource acquisition strategies are multidimensional. In the present study, a second axis (PC2) showed a trade-off of cocoa with dense, $\mathrm{N}$-rich roots in opposition to cocoa with less dense roots of higher $\mathrm{C}: \mathrm{N}_{\text {root }}$. This secondary axis explained close to $30 \%$ of total variation (Fig. 3; Table 1). Interestingly, coordinated root trait syndromes described by $\mathrm{PC} 2$ were more influenced by management than the root economics spectrum described by PC1, which suggests an important trade-off in the chemical and structural construction of fine roots in cocoa's overall 
Table 1 Trait loadings on the first two axes of principal component analyses of cocoa root traits: diameter (D), C:N in root tissue $\left(\mathrm{C}: \mathrm{N}_{\text {root }}\right)$, root tissue density (RTD), $\mathrm{N}$ content of roots $\left(\mathrm{N}_{\text {root }}\right)$, specific root area (SRA), length (SRL), and tip abundance (SRTA), absorptive/transport root length (A:T), fine root production (FRP). between traits and axes are indicated in italics $(p<0.05)$ Significant relationships

\begin{tabular}{|c|c|c|}
\hline & $\mathrm{PC} 1$ & $\mathrm{PC} 2$ \\
\hline \multicolumn{3}{|c|}{ Surface roots } \\
\hline $\mathrm{D}$ & $0.46^{* * *}$ & 0.02 \\
\hline RTD & $-0.28 * *$ & $-0.40 * * *$ \\
\hline $\mathrm{C}: \mathrm{N}_{\text {root }}$ & $0.32 * * *$ & $0.36^{* *}$ \\
\hline $\mathrm{N}_{\text {root }}$ & $-0.32 * * *$ & $-0.39 * * *$ \\
\hline SRA & -0.06 & $0.57 * * *$ \\
\hline SRL & $-0.42 * * *$ & $0.29 *$ \\
\hline SRTA & $-0.42 * * *$ & 0.23 \\
\hline $\mathrm{A}: \mathrm{T}$ & $-0.37 * * *$ & $0.24^{*}$ \\
\hline FRP & 0.09 & -0.21 \\
\hline \multicolumn{3}{|c|}{ Subsurface roots } \\
\hline $\mathrm{D}$ & $0.45^{* * *}$ & 0.19 \\
\hline RTD & -0.04 & $-0.48 * * *$ \\
\hline $\mathrm{C}: \mathrm{N}_{\text {root }}$ & 0.07 & $0.54 * * *$ \\
\hline $\mathrm{N}_{\text {root }}$ & -0.04 & $-0.51 * * *$ \\
\hline SRA & $-0.36^{* *}$ & $0.34^{* *}$ \\
\hline SRL & $-0.48^{* * *}$ & 0.09 \\
\hline SRTA & $-0.47 * * *$ & -0.12 \\
\hline A:T & $-0.39 * * *$ & 0.20 \\
\hline FRP & $0.23^{*}$ & 0.13 \\
\hline
\end{tabular}

Table 2 Results of two-way ANOVA of species combination and fertilization level on coordinated root strategies of cocoa. Significant effects are indicated in italics $(p<0.05)$

\begin{tabular}{lllll}
\hline Source & $d f$ & S.S. & $F$ value & $p$ value \\
\hline Surface roots & & & & \\
PC1 & & & & \\
$\quad$ Species combination & 2 & 11.24 & 1.349 & 0.286 \\
$\quad$ Fertilization level & 2 & 17.49 & 2.100 & 0.153 \\
Sp. comb. $\times$ Fert. & 4 & 4.85 & 0.291 & 0.880 \\
Residuals & 17 & 70.82 & & \\
PC2 & & & & \\
Species combination & 2 & 21.93 & 4.70 & 0.024 \\
Fertilization level & 2 & 6.10 & 1.31 & 0.296 \\
Sp. comb. $\times$ Fert. & 4 & 3.48 & 0.37 & 0.825 \\
Residuals & 17 & 39.63 & & \\
Subsurface roots & & & & \\
PC1 & & & & \\
Species combination & 2 & 22.36 & 3.51 & 0.053 \\
Fertilization level & 2 & 2.83 & 0.44 & 0.649 \\
Sp. comb. $\times$ Fert. & 4 & 22.38 & 1.75 & 0.185 \\
Residuals & 17 & 54.22 & & \\
PC2 & & & & 0.304 \\
Species combination & 2 & 39.17 & 22.40 & $<0.001$ \\
Fertilization level & 2 & 6.29 & 3.60 & 0.049 \\
Sp. comb. $\times$ Fert. & 4 & 4.60 & 1.32 & 0.304 \\
Residuals & 17 & 14.86 & & \\
\hline
\end{tabular}

acquisition strategy and response to management. Species composition had a significant effect on PC2 scores at both depth intervals (surface roots $p=0.014$; subsurface roots $p<0.001$ ) (Table 2; Fig. 2). Cocoa in monoculture tended to have denser, $\mathrm{N}$-rich roots (higher RTD and $\mathrm{N}_{\text {root }}$ ) than when in mixture with $E$. angolense at both depths, shown by the significantly lower PC2 axis scores (surface $p=0.020$; subsurface $p<0.001$ ) and also lower PC2 scores than cocoa roots in mixture with T. ivorensis, but significantly so only in subsurface roots $(p<0.001)$ and not in surface roots $(p=0.469)$. Interestingly, fertilization level had an effect in determining the coordinated resource acquisition strategies in subsurface roots $(p=0.049)$, which it did not in surface roots. There was significantly lower PC2 axis scores for subsurface roots in high fertilization compared to moderate fertilization $(p=0.049)$. Notably, in subsurface roots, FRP was positively associated with PC1, showing alignment with conservative root traits $(p<0.01)$, whereas in surface roots FRP was uncoordinated with PC1 $(p=0.380)$ and PC2 ( $p=0.076$ (Table 1). Broadly, these root trait syndromes seemingly characterize different strategies between root growth and placement versus morphological and physiological adjustments in relation to the soil environment. Notably, we show for the first time that the presence and activity of shade trees are critical in determining belowground response to fertilization as well as a tree crops' overall soil resource acquisition strategies. This is important for understanding crop function as well as interspecific interactions in multispecies agroecosystems.

\section{Conclusions}

Systematic variation in plant functional traits are known to relate with abiotic and biotic conditions, but much less is known on the direct and indirect effects of management practices on the expression of crop traits (Martin and Isaac 2015; Isaac et al. 2017; Damour et al. 2018). Root functional trait data for tree crops in the humid tropics are scarce. Our study characterizes fine root response of cocoa to active management strategies employed by farmers in low-input tropical agroecosystems. The existence of coordinated root trait strategies (e.g., root economics spectrum) among individuals of the same species within a farm indicates that plant trait-environment patterns previously only predicted across larger scales and across species may also apply to plantscale variation within a farm. Results from this study show that shifts in trait values and trait syndromes can be used as indicators of plant response to fertilizer application. For example, if root functional traits can be used to estimate foraging strategies of specific crops at specific sites, then farmers can more accurately apply fertilizer dosages catered to soil and management conditions. These more refined nutrient diagnostics and prescriptions are essential to maintain high nutrient use efficiency and minimize nutrient losses in tree-based agroecosystems. 
Acknowledgements We would like to thank Luke Anglaaere at CSIRForestry Research Institute of Ghana as well as Agyeman Kofi, Kirstie Cadger, and community members of South Formangso for the assistance in the field. We thank Serra Buchanan and Stephanie Gagliardi at University of Toronto Scarborough for assistance with laboratory work. We thank the anonymous reviewers who improved this article with their insightful comments.

Statement of data availability Data available from the corresponding author upon request.

Funding information This study was funded by the Natural Sciences and Engineering Research Council of Canada and the Department of Geography and Planning, University of Toronto.

\section{Compliance with ethical standards}

Declaration on conflict of interest The authors declare that they have no conflict of interests.

\section{References}

Borden KA, Thomas SC, Isaac ME (2019) Variation in fine root traits reveals nutrient-specific acquisition strategies in agroforestry systems. Plant Soil. https://doi.org/10.1007/s11104-01904003-2

Bordron B, Robin A, Oliveira IR, Guillemot J, Laclau JP, Jourdan C, Nouvellon Y, Abreu-Junior CH, Trivelin PCO, Gonçalves JLM, Plassard C, Bouillet JP (2018) Fertilization increases the functional specialization of fine roots in deep soil layers for young Eucalyptus grandis trees. For Ecol Manag:1-0. https://doi.org/10.1016/j.foreco. 2018.03.018

Chen GT, Tu LH, Peng Y, Hu HL, Hu TX, Xu ZF, Liu L, Tang Y (2017) Effect of nitrogen additions on root morphology and chemistry in a subtropical bamboo forest. Plant Soil 412:441-451. https://doi.org/ 10.1007/s11104-016-3074-z

Damour G, Navas ML, Garnier E (2018) A revised trait-based framework for agroecosystems including decision rules. J Appl Ecol 55:12-24. https://doi.org/10.1111/1365-2664.12986

Einsmann JC, Jones RH, Pu M, Mitchell RJ (1999) Nutrient foraging traits in 10 co-occuring plant species of contrasting life forms. J Ecol:609-619. https://doi.org/10.1046/j.1365-2745.1999.00376.x

Eissenstat DM, Kucharski JM, Zadworny M, Adams TS, Koide RT (2015) Linking root traits to nutrient foraging in arbuscular mycorrhizal trees in a temperate forest. New Phytol 208:114-124

Fort F, Cruz P, Lecloux E, de Oliveira LB, Stoia C, Theau J-P, Jouany C (2016) Grassland root functional parameters vary according to a community-level resource acquisition-conservation trade-off. J Veg Sci 27:749-758. https://doi.org/10.1111/jvs.12405

Freschet G, Roumet C (2017) Sampling roots to capture plant and soil functions. Funct Ecol 31:1506-1518. https://doi.org/10.1111/ijlh. 12426

Isaac ME, Ulzen-Appiah F, Timmer VR, Quashie-Sam SJ (2007) Early growth and nutritional response to resource competition in cocoashade intercropped systems. Plant Soil 298:243-254. https://doi.org/ 10.1007/s11104-007-9362-x

Isaac ME, Anglaaere LCN, Borden K, Adu-Bredu S (2014) Intraspecific root plasticity in agroforestry systems across edaphic conditions. Agric Ecosyst Environ 185:16-23. https://doi.org/10.1016/j.agee. 2013.12.004
Isaac ME, Martin AR, de Melo Virginio Filho E, Rapidel B, Roupsard O, Van den Meersche K (2017) Intraspecific trait variation and coordination: root and leaf economics spectra in coffee across environmental gradients. Front Plant Sci 8:1-13. https://doi.org/10.3389/fpls. 2017.01196

Kong D, Ma C, Zhang Q, Li L, Chen X, Zeng H, Guo D (2014) Leading dimensions in absorptive root trait variation across 96 subtropical forest species. New Phytol 203:863-872. https://doi.org/10.1111/ nph. 12842

Kramer-Walter KR, Laughlin DC (2017) Root nutrient concentration and biomass allocation are more plastic than morphological traits in response to nutrient limitation. Plant Soil:1-12. https://doi.org/10. 1007/s11104-017-3234-9

Liese R, Alings K, Meier IC (2017) Root branching is a leading root trait of the plant economics spectrum in temperate trees. Front Plant Sci 8:1-12. https://doi.org/10.3389/fpls.2017.00315

Malézieux E, Crozat Y, Dupraz C, Laurans M, Makowski D, OzierLafontaine H (2009) Mixing plant species in cropping systems: concepts, tools and models. A review. Agron Sustain Dev 29:4362. https://doi.org/10.1051/agro:2007057

Martin AR, Isaac ME (2015) Functional traits in agroecology: a blueprint for research. J Appl Ecol 52:1425-1435. https://doi.org/10.1111/ 1365-2664.12526

Martin AR, Rapidel B, Roupsard O, Van den Meersche K, de Melo Virginio Filho E, Barrios M, Isaac ME (2016) Intraspecific trait variation across multiple scales: the leaf economics spectrum in coffee. Funct Ecol:1-9. https://doi.org/10.1111/1365-2435.12790

McGrath D, Duryea M, Cropper W (2001) Soil phosphorus availability and fine root proliferation in Amazonian agroforests 6 years following forest conversion. Agric Ecosyst Environ 83:271-284

Mou P, Jones RH, Tan Z, Bao Z, Chen H (2013) Morphological and physiological plasticity of plant roots when nutrients are both spatially and temporally heterogeneous. Plant Soil 364:373-384. https://doi.org/10.1007/s11104-012-1336-y

Muñoz F, Beer J (2001) Fine root dynamics of shaded cacao plantations in Costa Rica. Agrofor Syst 51:119-130. https://doi.org/10.1023/A: 1010651203815

Ostonen I, Püttsepp Ü, Biel C, Alberton O, Bakker MR, Lõhmus K, Majdi H, Metcalfe D, Olsthoorn AFM, Pronk A, Vanguelova E, Weih M, Brunner I (2007) Specific root length as an indicator of environmental change. Plant Biosyst 141:426-442. https://doi.org/ 10.1080/11263500701626069

Prieto I, Roumet C, Cardinael R, Dupraz C, Jourdan C, Kim JH, Maeght JL, Mao Z, Pierret A, Portillo N, Roupsard O, Thammahacksa C, Stokes A (2015) Root functional parameters along a land-use gradient: evidence of a community-level economics spectrum. J Ecol 103:361-373. https://doi.org/10.1111/1365-2745.12351

Roumet C, Birouste M, Picon-Cochard C, Ghestem M, Osman N, Vrignon-Brenas S, Cao KF, Stokes A (2016) Root structurefunction relationships in 74 species: evidence of a root economics spectrum related to carbon economy. New Phytol:815-826. https:// doi.org/10.1111/nph.13828

van Vliet JA, Giller KE (2017) Mineral nutrition of cocoa: a review. Adv Agron 141:185-270. https://doi.org/10.1016/bs.agron. 2016.10.017

Vitousek PM, Naylor R, Crews T, David MB, Drinkwater LE, Holland E, Johnes PJ, Katzenberger J, Martinelli LA, Matson PA, Nziguheba G, Ojima D, Palm CA, Robertson GP, Sanchez PA, Townsend AR, Zhang FS (2009) Nutrient imbalances in agricultural development. Science 324:1519-1520. https://doi. org/10.1126/science. 1170261

Wang P, Diao F, Yin L, Huo C (2016) Absorptive roots trait plasticity explains the variation of root foraging strategies in Cunninghamia lanceolata. Environ Exp Bot 129:127-135. https://doi.org/10.1016/ j.envexpbot.2016.01.001 
Wang G, Liu F, Xue S (2017) Nitrogen addition enhanced water uptake by affecting fine root morphology and coarse root anatomy of Chinese pine seedlings. Plant Soil. https://doi.org/10.1007/s11104017-3283-0

Weemstra M, Sterck FJ, Visser EJW, Kuyper TW, Goudzwaard L, Mommer L (2017) Fine-root trait plasticity of beech (Fagus sylvatica) and spruce (Picea abies) forests on two contrasting soils. Plant Soil 415:175-188. https://doi.org/10.1007/s11104016-3148-y
Yan G, Chen F, Zhang X, Wang J, Han S, Xing Y, Wang Q (2017) Spatial and temporal effects of nitrogen addition on root morphology and growth in a boreal forest. Geoderma 303:178-187. https://doi.org/ 10.1016/j.geoderma.2017.05.030

Publisher's note Springer Nature remains neutral with regard to jurisdictional claims in published maps and institutional affiliations. 